\title{
Effects of a n-3 PUFA deficient diet on the expression of retinoid nuclear receptors, neurogranin and neuromodulin in rat brain
}

\author{
Benjamin BUAUD ${ }^{1,2}$ \\ Carole BOUE ${ }^{1}$ \\ Nicole $\mathrm{COMBE}^{1}$ \\ Paul HIGUERET ${ }^{2}$ \\ Véronique PALLET ${ }^{2}$ \\ ${ }^{1}$ ITERG - Département Nutrition Santé; \\ Université Bordeaux 1, \\ Avenue des Facultés, 33405 Talence \\ 2 Unité de Nutrition et Neurosciences, \\ Universités Bordeaux 1 et 2; \\ Université Bordeaux 1, \\ Avenue des Facultés, 33405 Talence \\ <v.pallet@istab.u-bordeaux1.fr>
}

\section{Introduction}

Brain is a tissue rich in lipids (about 5060 percent of its dry weight). Cerebral membranes are especially rich in n-6 and n-3 PUFAs; arachidonic (20:4 n-6, AA) and docosahexaenoic acids (22:6n-3, DHA) are their main representatives. These PUFAs are specifically present in membrane phospholipids such as phosphatidylethanolamine (PE).

According to literature [1], AA and DHA play fundamental roles, notably the second which is essential for structure and functional development of brain during prenatal and early life.

Since several years, the involvement of PUFAs in brain functioning is well studied. For instance, some studies performed in rodents fed with variable and controlled contents of $n-6$ and n-3 PUFAs evidenced an influence of PUFAs on cognitive processes [2, 3]. It emerges that decreased cerebral amounts of DHA resulting from dietary $n-3$ deficiency are associated with impaired cognitive function such as decreased learning performances and disorders of memory and attentiveness. In addition, data obtained in human [review in 4] reported that some neurological disorders (autism, schizophrenia, depression) could be related to a membrane PUFA deficiency.

Multiple roles have been described for PUFAs within the central nervous system (CNS) [5]. In addition to their impact on the membrane biophysical properties (with consequences on membrane fluidity, ionic transport and interaction with membrane proteins), and their involvement in regulation of neurotransmitter release and synthesis of biologically active oxygenated derivatives, PUFAs could have also a

\begin{abstract}
A$ lot of studies performed in rodents revealed that $n-3$ polyunsaturated fatty acid (PUFA) deficient diets could induce deficits of learning capacities but the mechanisms involved are not well known. Retinoic acid (RA) and its nuclear receptors (RAR and RXR) play a central role in the maintenance of cognitive processes and synaptic plasticity via its action on target genes that are neurogranin $(R C 3)$ and neuromodulin (GAP43). Given some interferences were described between the retinoid and fatty acid signaling pathways, we investigated the effects of a $\alpha$-linolenic acid (18:3n-3) deficient diet on retinoic acid nuclear receptors (RAR, and RXR), on GAP43 and $R C 3$, and on blood and brain fatty acid composition in rats at three times of diet: 3, 9 and 18 weeks. In blood and brain of these animals, we observed a severe $n-3$ PUFA deficit (18:3n-3, 20:5 n-3 and particularly 22:6n-3) associated with an increase in the n-6 PUFA content (mainly 22:5 n-6). Real-time PCR and western blot analysis allowed us to note that retinoid signaling, GAP43 and RC3 expression were affected in the striatum of the $n-3$ PUFA deprived rats.
\end{abstract}

Key words: $n-3$ PUFA deficient diet, retinoic acid nuclear receptors, brain, neurogranin, neuromodulin

transcriptional action. To modulate nuclear receptor-mediated transcription of genes [6], the nuclear receptors responsive to fatty acids (PPAR, peroxisome proliferator-activated receptors) have to form a functional transcriptional unit upon heterodimerization with RXR (retinoid $X$ receptor), one of the nuclear receptors of retinoids.

Vitamin A and retinoic acid (RA), its most potent natural metabolite, play a significant role within the CNS, not only during brain development but also in the function of the mature brain [7-9]. In brain, RA controls, via its nuclear receptors RAR (retinoic acid receptor) and RXR, the expression of genes involved in synaptic plasticity, memory [10] and cognitive processes [11]. Among RA target genes, there are those coding for two identified neuronspecific protein kinase substrates implicated in molecular mechanisms underlying synaptic plasticity and memory formation: the neurogranin or RC3 [12] and the neuromodulin or GAP43 [13]. These two proteins are expressed on both sides of the synaptic cleft and are considered as good markers of dendrite spine density.

In this context, we hypothesized that a modification of the bioavailability of the nuclear modulators that are PUFA (by establishing a n-3 PUFA deficiency), could induce modifications of nuclear receptor (RAR and RXR) expression patterns. These modified profiles were described in our laboratory as able to cause modifications of the expression of genes involved in synaptic plasticity (RC3 and GAP43) with consequences on the synaptic plasticity state. Alterations of this state have been described as responsible, at functional level, for disorders of memory performances.

Thus, the retinoid nuclear receptor (RAR and RXR) expression and that of neuromodulin and neurogranin were measured in striatum, a brain area involved in memory processes. Levels of mRNA and proteins were respectively measured by real time RT-PCR and western blot analysis. At last, plasma, red blood cell membrane and brain fatty acid patterns were investigated.

\section{Materials and methods}

\section{Experimental protocol}

Our study was performed with male rat pups at weaning (Wistar), randomly divided into two experimental groups designated as $n-3$ adequate $(n=22)$ and $n-3$ deprived $(n=20)$ diets. The first group received a n-3 PUFA adequate diet which consisted of a mixture of peanut and rapeseed oils in the same proportions $(50 / 50, v / v)$. The $18: 2 n-6 / 18: 3 n-3$ (LA/ALA) ratio amounted to 5 and was conformed to the current French recommendations. The second group fed a $\alpha$-linolenic acid (18:3 n-3) deficient diet, made of peanut oil; the LA/ALA ratio was equivalent to 232 . In the two diets, lipids represented $5 \%$ of the ration and globally exhibited the same proportions of SFA, MUFA and PUFA (table 1). All animals were fed and given water ad libitum. Each rat was weighed three times weekly; food intake was recorded daily. Rats fed the diets during three different periods: 3,9 and 18 weeks. At the end of each time, rats were sacrificed by decapitation. Blood and brain were rapidly 
removed, and individual brain sections (striatum) were dissected out and then stored at $-80{ }^{\circ} \mathrm{C}$ for subsequent analysis.

\section{RNA extraction and reverse transcription}

Total RNA was extracted from striatum by using TRIzol reagent (Invitrogen, France) according to the manufacturer's protocol. Purified RNA was quantified and assessed for purity by UV spectrophotometry. RNA samples were reverse-transcribed as previously described [14] with minor modifications: reversetranscription was conducted from $1 \mu \mathrm{g}$ of total RNA and each target gene was co-reversetranscribed with PPIB (cyclophilin B) as reference gene.

\section{Analysis of gene expression by using real-time $P C R$}

The polymerase chain reaction (PCR) was carried out involving a LightCycler system (Roche Diagnostics, Mannheim, Germany), and by using LightCycler DNA Master SYBR Green according to the manufacturer's instructions, as previously described [15].

Forward and reverse primers sequences used were as follows: PPIB sense $5^{\prime}$-GTT CTGGAAGGCATGGATGT-3', antisense 5'-TCC CCGAGGCTCTCTCTACT-3'; RAR $\beta$ sense 5'-CAGCTGGGTAAATACACCACGAA-3', antisense 5'-GGGGTATACCTGGTACAAATTCTGA3'; RXR $\beta \gamma$ sense 5'-AGGCAGGTTTGCCAAG CTTCTG-3', antisense 5'-GGAGTGTCTCCAA TGAGCTTGA-3'; RC3 sense 5'-GCTCCAAC CCAGACGACGATATTC-3', antisense 5'-CAC TCTCCGCTCTTTATCTTCTTC-3'; GAP43 sense 5'-AGAAAGCAGCCAAGCTGAGGAGG-3', antisense 5'-CAGGAGAGACAGGGTTCAGGTCG-3'. Quantification data were analyzed using the LightCycler Relative Quantification Software, 3.5. (Roche Diagnostics, Mannheim, Germany). The interest of this software is illus- trated in Féart et al. [15]. In our case, the calibrator was chosen among the rats fed the n-3 adequate diet.

\section{Western blot analysis}

Western blot analysis was performed on striatum of rats fed the two experimental diets for 18 weeks, according to the procedure described by Husson et al. [16] for the experiment concerning RC3 and $\beta$-actin, and as decribed by Husson et al. [17] for the expression of GAP43. The staining intensity of protein bands was determined using an image analyser (Quantity One, Biorad Laboratories, USA). The relative levels of RC3, GAP43 and $\beta$-actin proteins were determined as percent of $\mathrm{RC} 3$, GAP43 and $\beta$-actin respectively of $n-3$ adequate rats.

\section{Lipid analyses}

\section{Extraction of brain lipids}

Total lipids of brain were extracted by using the method of Folch et al. [18], with 20 volumes of chloroform/methanol (2/1, by vol.) per $\mathrm{g}$ of tissue. Extraction was made under agitation at room temperature; after $1 \mathrm{~h}, 0.2$ volumes of $\mathrm{KCl}(0.8 \%$ in water) were added per volume of extraction mixture. Hydroalcoolic and chloroformic phases were separated by centrifugation. The hydroalcoolic phase was removed and the chloroformic phase was washed with "upper phase". After centrifugation, the chloroformic phase was filtered and the pellet washed with chloroform/methanol (2/1, by vol.); then solvents were evaporated under vacuum, at room temperature with a rotary evaporator. The lipid extract was taken again with chloroform and filtered to obtain a chloroformic solution. The solvent was evaporated under nitrogen and dry extract was taken again with chloroform/methanol (2/1, by vol.). The final solution called "Folch extract" was stored at $-20^{\circ} \mathrm{C}$.

Table 1. Lipid composition of $n-3$ PUFA adequate and deficient diets.

\begin{tabular}{|lcc|}
\hline & Adequate & Deficient \\
\cline { 2 - 3 } Lipid content (g/100 g diet) & 5 & 5 \\
\hline Oil composition (g/100 g diet) & 2,5 & 0 \\
Rapeseed oil & 2,5 & 5 \\
Peanut oil & 1,25 & 1,25 \\
\hline Lipid contributions & 0,17 & 0,24 \\
SFA 1 (g/day) & 0,76 & 0,72 \\
MUFA (g/day) & 0,32 & 0,29 \\
PUFA (g/day) & 273 & 290 \\
18:2n-6 (mg/day) & 50 & 1,25 \\
$18: 3 n-3$ (mg/day) & 5 & 232 \\
$18: 2 n-6 / 18: 3 n-3$ & & \\
\hline
\end{tabular}

${ }^{1}$ SFA, saturated; MUFA, monounsaturated; PUFA.

Isolation of brain phosphatidylethanolamine

(PE)

Solvent of "Folch extract" was evaporated to dryness under a stream of nitrogen. Lipids were taken up in an appropriate volume of chloroform/methanol (2/1, v/v). Total phospholipids of brain were separated by thin layer chromatography (TLC) with using plates pre-coated with $0,35 \mathrm{~mm}$ silica gel $60 \mathrm{H}$ (Merck, France). A volume of "Folch extract" was deposed on silica gel; the solvent system used for separation was a mixture of chloroform/ methanol/acetic acid/water (75/45/12/6, by vol). After migration and revelation by DCF $(0.2 \%$ in ethanol), the silica gel area corresponding to PE was visualized under U.V. $(254 \mathrm{~nm})$, removed from the TLC plate and transferred in a glass tube for preparation of fatty acid methyl esters.

Preparation of fatty acid methyl esters (FAME) Total fatty acids of brain PE were methylated according to the method of Morrison and Smith [19]. $1 \mathrm{~mL}$ of boron trifluoride methanol solution (14\%; w/v) (SigmaChemical Co.) was added to the silica gel area corresponding to $\mathrm{PE}$ in a glass tube, maintained for $20 \mathrm{~min}$ at $90^{\circ} \mathrm{C}$ after closing. After addition of $1 \mathrm{~mL}$ of $\mathrm{NaOH}$ $(5 \mathrm{~N})$, FAME obtained were extracted three times with $2 \mathrm{~mL}$ of hexane. Hexanic phases were concentrated, washed with $1 \mathrm{~mL}$ of water and stored at $-20^{\circ} \mathrm{C}$.

\section{Plasma lipids}

Total fatty acids of plasma were methylated according to the method of Lepage and Roy [20]. $2 \mathrm{~mL}$ of methanol/benzene $(4 / 1, \mathrm{v} / \mathrm{v})$ were added to $400 \mu \mathrm{L}$ of plasma. Then, under agitation and at $0{ }^{\circ} \mathrm{C}, 200 \mu \mathrm{L}$ of acetyl chlorure were added, and this mix was maintained for 1 hour at $100{ }^{\circ} \mathrm{C}$ in a closed tube. To stop the reaction, $5 \mathrm{~mL}$ of $\mathrm{Na}_{2} \mathrm{CO}_{3} 6 \%(\mathrm{w} / \mathrm{v})$ were added to the mixture. After centrifugation, the upper phase containing FAME was removed and stored at $-20^{\circ} \mathrm{C}$.

\section{Analyses of FAME}

Analyses of total FAME were carried out on gas chromatograph equipped with a flameionization detector and a split injector. A fused-silica capillary column (BPX 70, $60 \mathrm{~m}$ $\times 0.25 \mathrm{~mm}$ i.d., $0.25 \mu \mathrm{m}$ film; SGE, France) was used with $\mathrm{H}_{2}$ as a carrier gas (inlet pressure: 1 bar). The split ratio was 1:70. The column temperature was programmed from $150 \mathrm{C}$ to $200^{\circ} \mathrm{C}$ at $1.5^{\circ} \mathrm{C} / \mathrm{min}$ for $25 \mathrm{~min}$, then from $200{ }^{\circ} \mathrm{C}$ to $225^{\circ} \mathrm{C}$ at $20^{\circ} \mathrm{C} / \mathrm{min}$ and held at $225^{\circ} \mathrm{C}$ until completion of the analysis (20 min). The injection port and the detector were maintained at 250 and $280^{\circ} \mathrm{C}$ respectively. The gas chromatography (GC) peaks were integrated using a SP 4400 integrator 
(Spectra Physics, San Jose, CA). Identification of each fatty acid methyl ester was made by comparison of retention time of authentic standards (Sigma Chemical Co.).

\section{Statistical analysis}

Values are given as means and standard errors of the mean (SEM). The statistical significance of differences between means was calculated by ANOVA followed by Student's t-test $(P<0.05)$ using Statgraphics Plus 5.1. software.

\section{Results and discussion}

\section{Retinoic acid nuclear receptor expression}

The retinoic acid nuclear receptor expression was studied in the striatum of rats fed the deficient diet for 3, 9 and 18 weeks.

In comparison with animals of the adequate group, animals fed the deficient diet exhibited i) after 3 weeks, no significant variation of expression of any nuclear receptors; ii) after 9 weeks, a strongly decreased expression of $\operatorname{RAR} \beta(-28.2 \%, p<0.001)$; iii) after 18 weeks, no significant variation of RAR $\beta$ expression.

Data have shown in many animal tissues that retinoid signaling pathway was susceptible to fatty acid supply [21] and consequently to the level of activity of their signaling pathway. So the deficient diet could lead to a decrease of the expression of retinoid receptors, as observed after 9 weeks, which would indicate a hypoactivity of the retinoid signaling pathway.

\section{Synaptic plasticity marker expression (table 2)}

The expression of neurogranin (RC3) and neuromodulin (GAP43) was investigated at the

Table 2. Influence of the deficient diet on the mRNA and protein expression (\% expression $/ n-3$ adequate diet) of neurogranin and neuromodulin in striatum.

\begin{tabular}{|lcccc|}
\hline & & 3 weeks & 9 weeks & 18 weeks \\
\hline RC3 $^{1}$ & mRNA & $98,18 \pm 4,55$ & $94,85 \pm 6,19$ & $86,21 \pm 3.5^{*}$ \\
& protein & $\mathrm{ND}^{2}$. & $\mathrm{ND}^{2}$. & $82.03 \pm 12.91^{* * *}$ \\
\hline GAP43 $^{1}$ & mRNA & $90,82 \pm 6,12$ & $92,93 \pm 4,04$ & $108,33 \pm 2,08$ \\
& protein & $\mathrm{ND}^{2}$ & $\mathrm{ND}^{2}$ & $76,42 \pm 10,45^{*}$ \\
\hline
\end{tabular}

Data represent the mean \pm SEM of measures performed on 6 rats.

${ }^{1}$ RC3, neurogranin; GAP43, neuromodulin.

${ }^{2} \mathrm{ND}$, not determined.

${ }^{*} \mathrm{P}<0.05 ;{ }^{* *} \mathrm{P}<0.01$; ${ }^{* * *} \mathrm{P}<0.001$, significantly different from adequate diet.

mRNA and protein levels. The $n-3$ deprived rats displayed i) after 3 and 9 weeks, no different RC3 and GAP43 mRNA contents between the two experimental groups; ii) after 18 weeks, a decreased expression of the two synaptic plasticity markers: - 14\% (at mRNA level) and $-18 \%$ (at protein level) for RC3; - 24\% (at protein level) for GAP43.

Considering the involvement of RAR $\beta$ in the regulation of RC3 and GAP43 expression, the lack of decreased expression of these two synaptic plasticity markers after 9 weeks is difficult to explain. This result suggests a possible regulation of RC3 and GAP43 expression by another signaling pathway as it has been reported by Guadano-Ferraz et al. [22] about the transcriptional induction of RC3 by thyroid hormone. Concerning the difference of expression between GAP43 mRNA and protein, Namgung and Routtenberg [23] have previously suggested a post-transcriptional regulation of this synaptic plasticity marker.

Regarding the consequences of such results, if we consider some bibliographic data showing that RC3 knockout mice have impaired synaptic plasticity and spatial learning [24], and as well as that decreased GAP43 expression was associated with reduced neuronal plasticity and learning [25], we can suppose that the $n-3$ deficiency could lead to similar cognitive alterations.

\section{Effects of the deficient diet on plasma and brain PE fatty acid composition}

\section{Plasma polyunsaturated fatty acid composition (table 3)}

The plasma n- 6 and n-3 PUFA composition of rats fed the deficient diet changed all along the study; these modifications consisted in i) an important decrease $(-80 \%)$ of the total $n-3$ PUFA proportions, for $\alpha$-linolenic acid (18:3 $n-3)$ as much as for long-chain derivatives (eicosapentaenoic 20:5 n-3, docosapentaenoic 22:5 n-3, and docosahexaenoic 22:6 n-3 acids); ii) a slight increased percentage $(+10 \%)$ of total n-6 PUFAs, specially arachidonic (20:4 $n-6)$ and docosapentaenoic (22:5 n-6) acids. Nevertheless, the linoleic acid (18:2 n-6) proportion was diminished, despite the same supply of both experimental diets. This suggests that this fatty acid is used for synthesis of the n-6 long-chain derivatives (20:4 and 22:5), because of the natural competition phenom-

Table 3. Influence of the deficient diet on plasma polyunsaturated fatty acid composition (\% of total fatty acids).

\begin{tabular}{|c|c|c|c|c|c|c|}
\hline \multirow[b]{2}{*}{$\begin{array}{l}\text { Polyunsaturated } \\
\text { fatty acids }{ }^{1}\end{array}$} & \multicolumn{2}{|c|}{3 weeks } & \multicolumn{2}{|c|}{9 weeks } & \multicolumn{2}{|c|}{18 weeks } \\
\hline & Adequate & Deficient & Adequate & Deficient & Adequate & Deficient \\
\hline $18: 2 n-6$ & $12,33 \pm 0,29$ & $11,24 \pm 0,36^{*}$ & $12,31 \pm 0,22$ & $10,78 \pm 0,25^{* * *}$ & $13,33 \pm 0,33$ & $12,02 \pm 0,35^{*}$ \\
\hline $20: 4 n-6$ & $22,98 \pm 0,74$ & $27,39 \pm 1,03^{*}$ & $19,76 \pm 0,85$ & $22,31 \pm 0,31^{*}$ & $18,72 \pm 0,57$ & $21,76 \pm 0,72^{\star *}$ \\
\hline $22: 5 n-6$ & $0,09 \pm 0,01$ & $1,82 \pm 0,12^{* * *}$ & $0,07 \pm 0,01$ & $1,32 \pm 0,12^{* * *}$ & $0,06 \pm 0,01$ & $1,41 \pm 0,13^{* * *}$ \\
\hline Total n-6 PUFA & $36,31 \pm 0,72$ & $41,67 \pm 0.74^{\star * *}$ & $32,96 \pm 0,75$ & $35,55 \pm 0,44^{*}$ & $33,27 \pm 0,67$ & $36,52 \pm 0,61^{* *}$ \\
\hline $18: 3 n-3$ & $0,7 \pm 0,05$ & $0,04 \pm 0.00^{* * *}$ & $0,87 \pm 0,04$ & $0,06 \pm 0,01^{* * *}$ & $0,68 \pm 0,03$ & $0,03 \pm 0,00 * * *$ \\
\hline $20: 5 n-3$ & $0,66 \pm 0,05$ & $0,03 \pm 0.00^{* * *}$ & $0,75 \pm 0,07$ & $n d^{2 * \star *}$ & $0,59 \pm 0,04$ & $n d .^{2^{\star \star \star}}$ \\
\hline $22: 5 n-3$ & $0,54 \pm 0,04$ & $0,09 \pm 0,01^{* * *}$ & $0,49 \pm 0,04$ & $0,06 \pm 0,01^{* * *}$ & $0,43 \pm 0,02$ & $0,09 \pm 0,01^{* * *}$ \\
\hline $22: 6 n-3$ & $3,43 \pm 0,11$ & $0,84 \pm 0,04^{* * *}$ & $2,98 \pm 0,11$ & $0,55 \pm 0,03^{* * *}$ & $2,56 \pm 0,07$ & $0,8 \pm 0,02^{* * *}$ \\
\hline Total n-3 PUFA & $5,33 \pm 0,10$ & $1,00 \pm 0.005^{* * *}$ & $5,09 \pm 0,09$ & $0,66 \pm 0.02^{* * *}$ & $4,27 \pm 0,09$ & $0,72 \pm 0,03^{* * *}$ \\
\hline
\end{tabular}

Data represent the mean \pm SEM of measures performed on 6 rats.

${ }^{1}$ Polyunsaturated fatty acid abbreviations: $18: 2 n-6$, linoleic; 20:4n-6, arachidonic; 22:5n-6, docosapentaenoic; 18:3n-3, $\alpha$-linolenic; 20:5n-3, eicosapentaenoic; 22:5n-3, docosapentaenoic; and 22:6n-3, docosahexaenoic acids. PUFA, polyunsaturated fatty acids.

2 nd., not detected.

${ }^{*} P<0.05 ;{ }^{* *} P<0.01 ;{ }^{* * *} P<0.001$, significantly different from adequate diet. 
Table 4. Influence of the deficient diet on brain phosphatidylethanolamine (PE) polyunsaturated fatty acid composition (\% of total fatty acids).

\begin{tabular}{|c|c|c|c|c|c|c|}
\hline \multirow[b]{2}{*}{$\begin{array}{l}\text { Polyunsaturated } \\
\text { fatty acids }{ }^{1}\end{array}$} & \multicolumn{2}{|c|}{3 weeks } & \multicolumn{2}{|c|}{9 weeks } & \multicolumn{2}{|c|}{18 weeks } \\
\hline & Adequate & Deficient & Adequate & Deficient & Adequate & Deficient \\
\hline $18: 2 n-6$ & $0,28 \pm 0,02$ & $0,21 \pm 0,01^{*}$ & $0,2 \pm 0,00$ & $0,17 \pm 0.01^{* \star *}$ & $0,39 \pm 0,02$ & $0,36 \pm 0,02$ \\
\hline $20: 4 n-6$ & $10,35 \pm 0,17$ & $10,9 \pm 0,21$ & $9,2 \pm 0,07$ & $10,35 \pm 0,09^{\star * *}$ & $9,43 \pm 0,09$ & $10.27 \pm 0.13^{* \star *}$ \\
\hline $22: 5 n-6$ & $0,91 \pm 0,03$ & $3,88 \pm 0,12^{* * *}$ & $0,46 \pm 0,02$ & $4,16 \pm 0,07^{* \star *}$ & $0,41 \pm 0,01$ & $4,52 \pm 0,10^{* * *}$ \\
\hline Total n-6 PUFA & $17,56 \pm 0,19$ & $21,5 \pm 0,35^{* * *}$ & $15,2 \pm 0,09$ & $20,98 \pm 0,15^{* * *}$ & $15,56 \pm 0,11$ & $21,45 \pm 0,21^{* \star *}$ \\
\hline $22: 5 n-3$ & $0,26 \pm 0,01$ & $0,12 \pm 0,00^{* * *}$ & $0,23 \pm 0,01$ & $0,06 \pm 0,00^{* * *}$ & $0,18 \pm 0,00$ & $0,04 \pm 0,00^{* * *}$ \\
\hline $22: 6 n-3$ & $17,42 \pm 0,49$ & $14,49 \pm 0,35^{* * *}$ & $16,62 \pm 0,31$ & $12,88 \pm 0.20^{* * *}$ & $14,91 \pm 0,15$ & $10,33 \pm 0,20^{* * *}$ \\
\hline Total n-3 PUFA & $17,88 \pm 0,49$ & $14,61 \pm 0,35^{* * *}$ & $16,88 \pm 0,31$ & $12,93 \pm 0,20^{* * *}$ & $15,09 \pm 0,15$ & $10,37 \pm 0,20^{* * *}$ \\
\hline
\end{tabular}

Data represent the mean \pm SEM of measures performed on 6 rats.

${ }^{1}$ Polyunsaturated fatty acid abbreviations: 18:2n-6, linoleic; 20:4n-6, arachidonic; 22:5n-6, docosapentaenoic; 22:5n-3, docosapentaenoic; and 22:6n-3, docosahexaenoic acids. PUFA, polyunsaturated fatty acids.

${ }^{*} P<0.05 ;{ }^{* * *} P<0.001$, significantly different from adequate diet.

enon between $n-6$ and n-3 fatty acids towards enzymes of the fatty acid metabolism; in the deficient group, preference is given to the $n-6$ fatty acids.

At the same time, we studied the total fatty acid composition of red blood cell membranes, as described previously [26]. This membrane model gives indications about the incorporation ability of dietary fatty acids into cell membranes. The same patterns as those observed in plasma were obtained for $n-6$ and n-3 PUFAs. The study of the plasma total fatty acid composition is of very particular interest because it is an indicator of fatty acids usable by brain [27]. Some authors [28] reported that low plasma DHA content was a significant risk factor for the development of Alzheimer disease and appeared to be common in cognitive impairment with aging. Others [29], in epidemiological studies, evidenced in old subjects, that a higher proportion of n- 6 PUFAs and a lower n-3 PUFA content in erythrocyte membrane were associated with a greater risk of cognitive decline, diverse neuropsychiatric and neurodegenerative diseases.

\section{Brain phosphatidylethanolamine polyunsaturated fatty acid composition (table 4)}

Phosphatidylethanolamine (PE), with phosphatidylcholine, is the most abundant phospholipid in rat cerebral membranes but especially the richest in DHA.

Like in plasma, total n-6 and n-3 PUFA proportions were modified by the deficient diet but in a different way, i) the n-6 DPA (22:5 n-6) percentage was extensively increased as the survey went $(+326 \%$ after 3 weeks and $+1002 \%$ after 18 weeks); ii) concomitantly, the DHA proportion was diminished $(-17 \%$ and $-31 \%$, after 3 and 18 weeks respectively). Data of the literature mentioned that a declined brain DHA percentage was balanced by an increase of the n-6 DPA rate in order to maintain the membrane insaturation rate.
Thus, in the experimental conditions tested, cerebral membranes were impoverished in DHA. Considering its involvement in brain functioning and its ability to bind RXR [30], the loss of DHA could have neurological consequences. This assumption is in accordance with some results [31] that described poorer performance in spatial tasks concomitantly to a loss of brain DHA. Others [32] demonstrated, by studying the effects of a n-3 PUFA deprived diet in rat, that the resulting disturbed brain PUFA metabolism (elevated n- 6 DPA and reduced DHA proportions) may be involved in human depression, aggression, and bipolar disorder.

These data are just preliminary results of a wide work about the effects of PUFA dietary contributions on the brain vitamin A action. Other measures of nuclear receptor expression have to be done in striatum and in another brain area implicated in memory processes (hippocampus).

Acknowledgments. This research was supported by Oniol, ANRT, Société Lesieur and Conseil Régional d'Aquitaine. The authors sincerely thank Laurent Caune (Unité Nutrition et Neurosciences) for animal care, and Laurence Fonseca and Sabrina Serrano (ITERG, Département Nutrition Santé) for their valuable contribution to fatty acid analyses.

\section{REFERENCES}

1. HORROCKS LA, YEO YK. Health benefits of docosahexaenoic acid (DHA). Pharmacol Res 1999; 40(3): 211-25.

2. MORIGUCHIT, GREINER RS, SALEM IR. N Behavioral deficits associated with dietary induction of decreased brain docosahexaenoic acid concentration. / Neurochem 2000; 75(6): 2563-73.
3. GREINER RS, MORIGUCHIT, HUTTONA. SLOTNICK BM, SALEM N Jr. Rats with low levels of brain docosahexaenoic acid show impaired performance in olfactory-based and spatial learning tasks. Lipids 1999; 34(Suppl): S239S243.

4. ALESSANDRI IM, GUESNET P, VANCASSEL $S$, et al. Polyunsaturated fatty acids in the central nervous system: evolution of concepts and nutritional implications throughout life. Reprod Nutr Dev 2004; 44(6): 509-38.

5. ALESSANDRI JM, GUESNET P. Multiple facets of membrane lipids and the diversity of their action mode with special emphasis on the central nervous system. Reprod Nutr Dev 2005; 45(5): 529-33.

6. BARCELO-COBLIJN G, HOGYES E, KITAJKA K, et al. Modification by docosahexaenoic acid of age-induced alterations in gene expression and molecular composition of rat brain phospholipids. Proc Natl Acad Sci USA 2003; 100(20): 11321-6.

7. MADEN M, GALE E, ZILE M. The role of vitamin $A$ in the development of the central nervous system. / Nutr 1998; 128(2 Suppl): 471S-475S.

8. MALIK MA, BLUSZTAJN JK, GREENWOOD CE. Nutrients as trophic factors in neurons and the central nervous system: role of retinoic acid. I Nutr Biochem 2000; 11(1): 2-13.

9. LANE MA, BAILEY SJ. Role of retinoid signalling in the adult brain. Prog Neurobiol 2005; 75(4): 275-93.

10. IKEGAYAY, ISHIZAKAY, MATSUKIN. BDNF attenuates hippocampal LTD via activation of phospholipase C: implications for a vertical shift in the frequency-response curve of synaptic plasticity. Eur J Neurosci 2002; 16(1): 145-8.

11. CHIANG MY, MISNER D, KEMPERMANN G, et al. An essential role for retinoid receptors RARbeta and RXRgamma in long-term potentiation and depression. Neuron 1998; 21(6): 1353-61. 
12. INIGUEZ MA, MORTE B, RODRIGUEZ-PENA A, et al. Characterization of the promoter region and flanking sequences of the neuron-specific gene RC3 (neurogranin). Brain Res Mol Brain Res 1994; 27(2): 205-14.

13. SAUNDERS DE, HANNIGAN JH, ZAJAC CS, WAPPLER NL. Reversal of alcohol's effects on neurite extension and on neuronal GAP43/B50, $\mathrm{N}$-myc, and c-myc protein levels by retinoic acid. Brain Res Dev Brain Res 1995; 86(1-2): 16-23.

14. DELAGE B, BAIRRAS C, BUAUD B, PALLET V, CASSAND P. A high-fat diet generates alterations in nuclear receptor expression: prevention by vitamin $A$ and links with cyclooxygenase- 2 and beta-catenin. Int / Cancer 2005; 116(6): 839-46.

15. FEART C, MINGAUD F, ENDERLIN V, et al. Differential effect of retinoic acid and triiodothyronine on the age-related hypo-expression of neurogranin in rat. Neurobiol Aging 2005; 26: 729-38.

16. HUSSON M, ENDERLIN V, ALFOS S, FEART C, HIGUERET $P$, PALLET V. Triiodothyronine administration reverses vitamin A deficiencyrelated hypo-expression of retinoic acid and triiodothyronine nuclear receptors and of neurogranin in rat brain. Br J Nutr 2003; 90: 191-8.

17. HUSSON M, ENDERLIN V, ALFOS S, BOUCHERON C, PALLET V, HIGUERET P. Expression of neurogranin and neuromodulin is affected in the striatum of vitamin A-deprived rats. Brain Res Mol Brain Res 2004; 123(1-2): 7-17.
18. FOLCH I, LEES M, SLOANE STANLEY GH. A simple method for the isolation and purification of total lipides from animal tissues. I Biol Chem 1957; 226(1): 497-509.

19. MORRISON WR, SMITH LM. Preparation of fatty acid methyl esters and dimethylacetals from lipids with boron fluoride-methanol. J Lipid Res 1964; 5: 600-8.

20. LEPAGE G, ROY CC. Specific methylation of plasma nonesterified fatty acids in a one-step reaction. J Lipid Res 1988; 29(2): 227-35.

21. REDONNET A, GROUBET R, NOEL-SUBERVILLE C, BONILLA S, MARTINEZ A, HIGUERET P. Exposure to an obesity-inducing diet early affects the pattern of expression of peroxisome proliferator, retinoic acid, and triiodothyronine nuclear receptors in the rat. Metabolism 2001; 50(10): 1161-7.

22. GUADANO-FERRAZ A, ESCAMEZ MJ, MORTE $B$, VARGIU P, BERNAL J. Transcriptional induction of RC3/neurogranin by thyroid hormone: differential neuronal sensitivity is not correlated with thyroid hormone receptor distribution in the brain. Brain Res Mol Brain Res 1997; 49: 37-44.

23. NAMGUNG U, ROUTTENBERG A. Transcriptional and post-transcriptional regulation of a brain growth protein: regional differentiation and regeneration induction of GAP-43. Eur J Neurosci 2000; 12(9): 3124-36.

24. PAK JH, HUANG FL, LI J, et al. Involvement of neurogranin in the modulation of calcium/calmodulin-dependent protein kinase II, synaptic plasticity, and spatial learning: a study with knockout mice. Proc Natl Acad Sci USA 2000; 97(21): 11232-7.
25. MOLTENI R, BARNARD RJ, YING Z, ROBERTS CK, GOMEZ-PINILLA F. A high-fat, refined sugar diet reduces hippocampal brainderived neurotrophic factor, neuronal plasticity, and learning. Neuroscience 2002; 112(4): 803-14.

26. MORISE A, COMBE N, BOUE C, et al. Dose effect of $\alpha$-linolenic acid on PUFA conversion, bioavailability, and storage in the hamster. Lipids 2004; 39: 325-34.

27. SPECTOR AA. Plasma free fatty acid and lipoproteins as sources of polyunsaturated fatty acid for the brain. / Mol Neurosci 2001; 16(2-3): 159-65; (discussion 215-21).

28. CONQUER JA, TIERNEY MC, ZECEVIC I, BETTGER W], FISHER RH. Fatty acid analysis of blood plasma of patients with Alzheimer's disease, other types of dementia, and cognitive impairment. Lipids 2000; 35(12): 1305-12.

29. HEUDE B, DUCIMETIERE P, BERR C. Cognitive decline and fatty acid composition of erythrocyte membranes-The EVA Study. Am / Clin Nutr 2003; 77(4): 803-8.

30. DE URQUIZAAM, LIU S, SJOBERG M, et al. Docosahexaenoic acid, a ligand for the retinoid $X$ receptor in mouse brain. Science 2000; 290(5499): 2140-4.

31. SALEM Jr. N, MORIGUCHI T, GREINER RS, et al. Alterations in brain function after loss of docosahexaenoate due to dietary restriction of n-3 fatty acids. / Mol Neurosci 2001; 16(2-3): 299-307; (discussion 317-21).

32. DEMAR JR. JC, MA K, BELL JM, IGARASHI M, GREENSTEIN D, RAPOPORT SI. One generation of n-3 polyunsaturated fatty acid deprivation increases depression and aggression test scores in rats. J Lipid Res 2006; 47(1): 172-80. 